\section{IJ§ER}

ISSN: 2149-5939
International Journal of Social Sciences and Education Research

Online, http://dergipark.gov.tr/ijsser

Volume: 1(2), 2015

\title{
Fotoğrafın manipülasyon ve gündem saptama gücü
}

\section{The power of the photograph in terms of manipulation and agenda setting}

\author{
Gökhan Demirel1
}

Received Date: 01 / 02 / 2015

Accepted Date: 01 / 04 / 2015

$\ddot{O} z$

Fotoğrafin serüveni uzun yıllara dayanır. Bu süreçte fotoğrafin sanat mı değil mi, fotoğraf ile fotoğrafçının vicdan muhakemesi, fotoğrafin gerçek mi yoksa kurgu mu olduğu gibi pek çok tartışma da beraberinde gelmiştir. Fotoğrafin gelișim hızı oldukça etkileyicidir ve bu bilimsel bir gerçektir. DSRL makinalar, photoshop programları, akıllı telefonlar ve instagram gibi pek çok fotoğraf uygulamalar fotoğrafin gelişmesine ve popüler olmasında oldukça etkili olmuşlardır. Fotoğrafin bu kadar ucuz ve pratikleşmiş olması, fotoğraf çeken araçlara erişimi kolaylaştırmış ve fotoğraf çeken kişi sayısında oldukça fazla bir rakama ulaşmasına vesile olmuştur. Son yılların modası olan sosyal medya araçları da insanların çektikleri fotoğraflarını başkalarıyla paylaşma imkanı sağlamıştır. Fotoğraf alanındaki bu hızl gelişmelerin fotoğraf sanatına fayda să̆ladığı doğrudur, ancak bir de madalyonun diğer yüzü vardır. Fotoğrafin amacı, fotoğrafçının objektifini nereye çevirdiğine karar vermesinden itibaren başlar. Çekilen fotoğrafin nereden kırpılacă̆ına, hangi yayın kuruluşunda yayınlanacağına ve fotoğrafin altına hangi başlığın yazılacağına karar vermek, tüm bunlar fotoğrafin kitle üzerinde bırakacağı etkiyi doğrudan etkileyen faktörlerdir. Fotoğrafin evrensel bir dil kullanıyor olması, sözlü ve yazılı öğelere kıyasla daha kalıcı etki yaratıyor olması, onu gündem oluşturmak için oldukça cazip bir öğe haline getirmektedir. Manipüle edilen bir kaç fotoğraf ile kamuoyu oluşturabilirsin, savaş başlatabilir ya da savaşları bitirebilirsin. Bu da fotoğrafin ne kadar güçlü olduğunu ve neden propaganda aracı olarak kullanıldı̆̆ını açıklamaktadır.

Anahtar sözcükler: Fotoğraf, manipülasyon, gündem, güç, kamuoyu

\begin{abstract}
The adventure of the photograph has a long story. This adventure leads to many debates, such as whether or not photography is an art, or what should a photographer do when he/she stands against an ethical situation or if the photograph is genuine or is it all a fiction. The acceleration of photography is highly impressive and scientifically evident. Photography has become practical, most popular and pretty cheap with the developing DSL cameras, computer apps such as photoshop, smart phones and its apps such as instagram which uses effective photo-filters. Since it is cheap and practical, reaching photography equipment has become easier than ever and results in a growing number of population interested in photography. Thanks to the latest trend social networks, now people can easily share their photographs with others. It is true that this development has helped the art of photography. Nonetheless, there are two sides to every coin. On one hand, the popularity of photography obviously seems advantageous. Yet, on the other hand the photograph begins at the very moment the Photographer makes a decision on where to stand behind the camera and how s/he chooses to place his/her objective. How will it be cropped, where will it be published, and what will be written below it, the answers to all these questions affect public opinions directly, and not everyone is capable of making such decisions. Photography has an universal language, which makes it more effective than verbal or written products. This makes it a popular agenda which sets the status quo. With only a handful of manipulated photographs, you can change the opinions of a whole society. You can start or end wars just by changing the direction of your objective according to your own intentions. This explains the power of photography why it is a popular propaganda organ.
\end{abstract}

Keywords: Photography, manipulation, agenda setting, photo power

\footnotetext{
${ }^{1}$ Ege University, Faculty of Communication, IZMIR/TURKEY, gokhan.demirel@ege.edu.tr
} 
Demirel, G. (2015). Fotoğrafın manipülasyon ve gündem saptama gücü. International Journal of Social Sciences and Education Research, 1 (2), 625-636.

\section{Giriş}

Fotoğraf yolculuğu, insanoğlunun mağara duvarlarına gördüklerini resmetmelerine kadar uzanan bir yolculuktur. İlk insan, çevresinde gördüklerini anlamlandırmak, grubundaki diğer insanlara anlatmak veya tekrar görebilmek için, kilden boyalarla duvarlara figürler çizmiş ya da gördüklerini doğrudan duvarlara kazımıştır. İlk insanın gördüklerini saklama davranışı yaşadığımız çağa kadar devam etmektedir. Günümüz dünyasında saklama koşulları değişmiş ve çeşitlenmiştir sadece. Fotoğraflamak ise bu konuda en çok başvurulan yöntem olmuştur.

\section{Literatür}

Fotoğraf; çekenine göre anlamı değişen bir kavramdır. Ancak en temelinde, 1şıkla boyamak anlamına gelir, bu tanım eski Yunancaya dayanır. Antik Yunancada "Photos" 1şık, "Grapho" ise yazmak anlamına gelir, Grapho'nun orjinali ise kayalara kabartma ya da çizik atmak anlamına dayanmaktadır(Czaja, 1973, s.7). İnsanların binlerce yıl önce yaptıkları "Grapho", fotoğrafın ilk adımlarıdır denilebilir. Başka bir deyişle, bu onların bir şeyleri saklamak için başvurdukları yöntemleriydi. O dönemden bu yana görüleni saklama arzusu devam etmiş ve fotoğraf insanların en temel uğraşlarından biri haline gelmiştir. Fotoğraf insanların dünya görüşünü, birikimini en çok etkilemiş ve etkileyen medyadır. Fotoğraf, dünyamızda herşeyi en yakından gören tanıktır. Fotoğraf, dünyamızdan, yaşamdan yapılan alıntılardır(Çizgen,1992:65). Fotoğraf gündelik hayatın bir parçası halindedir artık.

Fotoğrafın gündelik hayatta bu kadar çok kullanılıyor olmasının nedeni, günümüz optik teknolojisinin hızlı gelişimi fotoğraf makinalarının çeşitlenip, kullanımlarının pratikleşmiş olmasıdır. Bunun yanında fotoğraf araç gereçlerinin de çeşitlenmesi, sektörde farklı markaların üretime katılmasıyla, ürünlerin daha da çeşitlenip maliyet olarak ucuzlaması, filmli makinalardan DSLR denilen dijital makinalara geçilmesi, ucuzluk ve pratikliğin yanında bir de kullanıcıya hız kazandırmış oldu.

Klasik teknoloji denilebilecek olan, sanayi teknolojisinin yanı sıra gelişen dijital teknoloji de fotoğraf kavramının gelişmesine katkı sağlamıştır. Daha doğru bir ifadeyle, bu iki teknoloji birbirinden destek alarak ilerlerler. Sanayi teknolojisi, neredeyse her bireyin cebine bir adet akıllı telefon ve fotoğraf çeken diğer araç gereçleri koymuştur. Dijital teknoloji de bu akıllı telefonlara facebook, twiter, instagram gibi sosyal ağ uygulamaları koyarak, bu uygulamaların da anında fotoğraf çekip paylaşılmasına imkan sağlamıştır. Bu uygulamalar üzerinden çekilen fotoğrafların anında paylaşılması beraberinde bilinirliği de getirerek daha çok insana ulaşılmasını sağlamıştır. Bununla birlikte daha çok fotoğraf uygulamaları piyasaya çıkarak fotoğraflara anında dijital filtreler uygulama imkanı sağlanmıştır. Filtresiz çekilen bir fotoğrafın göreceli olarak filtrelendikten sonra daha çok beğenilip paylaşılması da bu filtreli uygulamaların popüler olmasını sağlamış ve fotoğraf seven, çeken kişi sayısında ciddi bir artış olmasına neden olmuştur. Öyle ki; instagram fotoğrafçılığı, mobil fotoğrafçılık gibi, farklı fotoğraf dalları ortaya çıkmış oldu.

Fotoğraf çekmek ile fotoğrafçı farklı kişilerdir. Dolayısıyla bu kadar çok fotoğraf çeken kişinin olmasına rağmen, fotoğrafçının bu kadar çok sayıda olmaması, fotoğrafın sadece deklanşöre ya da başka bir tuşa basmakla aynı anlama gelmediğini göstermektedir. Bill Smith kitabında söyle belirtmektedir; "her ailede fotoğraf makinası olmasına rağmen, o kadar sayıda iyi fotoğrafçı yoktur. Fotoğraf çekim aşaması bir çocuğun yapacağı kadar basittir ancak; özel bir görüntü saniyenin 1/500 hızında tam bir netlikle görmeyi gerektirir. Bir görüntünün bütününü görebilme yeteneği 
Demirel, G. (2015). The power of the photograph in terms of manipulation and agenda setting. International Journal of Social Sciences and Education Research, 1 (2), 625-636.

bir fotoğrafçıyı sıradan kamera kullanıcısından ayıran özelliktir”'(Smith, 200, s.8). Gültekin Çizgen aynı konuya şu şekilde açıklama getirmiştir; "Fotoğraf özellikle de japon optik sanayilerinin çok beccerikli üretim teknikleri ve satış kampanyalarıyla kamerayı bir ihtiyaç olarak tüketim ekonomilerine sokmalarından bu yana, geometrik olarak gelişti, fotoğraf artık, teknik uygulamaların da yaslandığı alt yapılarıyla, büyük kolaylıkla üretilebilmekte. Ancak her fotoğraf makinası sahibinin bir fotoğraf sanatçısı olduğunu düşünmek asla mümkün değildir”(Çizgen, 1992, s.11).

Fotoğrafçının, bakmaktan çok görmesi, hissetmesi gerekmektedir. Görme yeteneği onu diğer insanlardan ayıracak olan en önemli özelliği olacaktır. Görmek ile bakmak arasında fark ise, etrafına bilinçli bir şekilde bakmaktır. Bilinçli bir şekilde bakmak, ya da 'algılamak' belki de 'görmek’ kelimesinin yerine kullanılabilecek en iyi kelimedir. Çünkü, bazı şeyleri öğrenmek, tamamen kavramak ve hissetmek için en ideal kelimedir. Bazı şeyler dokunarak, tadarak ya da duyarak algılanır ancak, özellikle de bazı şeyler özellikle görerek algılanıp hissedilir(Czaja, 1973, s.7). işte bu yüzden fotoğrafçının sıradan kamera kullanıcısından farklı bakması, görmesi, alanında uzman olması gerekir. Fotoğraf bir başka deyişle 1şık demektir. Tıpkı görmek için 1şığa ihtiyaç duyulduğu gibi, fotoğraf için de 1şık elzemdir ve bunu hemen hemen herkes bilir. Ancak görmesini bilen fotoğrafçının 1şığın peşinden koşması, 1şığı algılaması gerekir, 1şığın oldukça farkında olmalı, 1şığı görmelidir ya da daha önce de belirtildiği gibi 1şığı hissetmek zorundadır. Işık bir fotoğrafçının, kalemi, fırçasıdır. Dolayısıyla fotoğraf sanatçısının, basit haliyle ışığa ihtiyaç duymanın yanında, ışığı iyice öğrenmesi, hissetmesi gerekmektedir. Fotoğraf sanatçısı Czaja; ışığın insanın doğduğundan beri etrafında olduğunu ancak, ışığın şaşırtmasına izin verildiği sürece ya da gece olduğunda 1şık özlendiği sürece gerçek bir fotoğrafçı olunacağını belirtir(Czaja, 1973, s.11). İnsanlar yaşadıkları bazı anları, hissettikleri bazı duyguları anlatmak için kelimeleri yetersiz bulduğu zamanlarda fotoğrafa sarılmışlardır. Dolayısıyla fotoğraf yeni bir dil, kelimelerin yetersiz kaldığı durumlarda en iyi anlatım aracı olmuştur. Zira görme konuşmadan önce oluşmuştur. Buna da bir nevi öze dönme hareketi denilebilir.

Fotoğraf tamamen görsel öğelere dayanan bir gözlem sanatıdır. Gerçeğin temsili ve zaman içinde anları donduran bir araç olmuştur. Fotoğrafın zamanı durdurması işleviyle diğer sanat dallarında olmayan bir dili vardır. Bu özelliğiyle farklı bir ritim yakalayan fotoğraf, gerçeğe en yakın görüntüyü yakalayarak gerçeğin sınırlarını zorlar. Ancak tüm bu özelliklerinin yanında fotoğrafın en temel işlevi, görmek, saklamak ve göstermektir. Fotoğraf sanatçısı Çizgen'e göre, fotoğraf mimetik (doğayı taklit etmek) sanatlar içinde gerçeğe en yakın görüntüyü veren sanat dalıdır ve fotoğrafın sanat olgusu üzerindeki tartışmaların kaynağı da burdan gelmektedir(Çizgen, 1992, s.40). Diğer tüm görsel sanatlar gibi fotoğrafçılık da "görmek, yakalamak, sergilemek" gibi yaratıcılığın 3 temel prensibi üzerinden şekillenir. Bu adımların her biri farklı yetenek ve beceri gerektirir. Üretilen bir fotoğrafın yaratıcılık süzgecinden geçerek sergilendiğine inanan Kirkman, fotoğraf sanatçısına şu soruları sorar; "Fotoğraflarını yaratıcılık sürecinin bir basamağı olarak mı sergiliyorsun, yoksa onları işlem sırasında bir ya da iki kez seyredip çekmece ya da bir kutuya mı koyarsın? Tüm yaratıcılık sürecini göz önüne aldığında, neden asla gün yüzüne çıkmayacak bir fotoğraf yaratıyorsun? Bu sorularda asıl vurgulanan üretilen eserin sergilenmeye hak kazandığıdır. Ona göre; yetenekli bir fotoğrafçının şaheseri saklansaydı eğer, bu bir israf olur ve kimse tarafından da bir daha da görünmezdi(Kirkman, 1983, s.6). Kirkman, fotoğrafın gösterme özelliğinin önemini bu şekilde belirtmiştir. Fotoğrafçı kendi dünyasını seçtiği konuları düzenlemekle, onları fotoğraflamakla oluşturur. Her fotoğrafçının objektifini yönlendirdiği öğeler farklıdır, hatta aynı konudan iki farklı fotoğrafçının yarattığı dünya bile bambaşka olabilmektedir. "Doğru yer- 
Demirel, G. (2015). Fotoğrafın manipülasyon ve gündem saptama gücü. International Journal of Social Sciences and Education Research, 1 (2), 625-636.

den, doğru zamanda yapılan bir düzenlemeyle fotoğrafın yaratım sorunları özgün bir şekilde çözümlenebilir(Çizgen, 1992, s16).

Fotoğraf gündelik hayatın bir oldukça işlevsel bir parçası haline gelmiştir. Fotoğrafın gündelik hayatın içerisine bu kadar hızlı dahil olması, özellikle de yüksek ücretli dijital kameralarla yarışır hale gelen yüksek çözünürlüklü akıllı telefonların büyük miktarda ve dijital fotoğraf makinalarına göre daha ucuz bir fiyatla piyasaya sürülmüş olmasından kaynaklanmaktadır. Bunlara takiben yukarda bahsedilen sosyal medya araçlarının insanlar tarafından etkin bir şekilde kullanılması, özellikle de toplumsal olaylarda kolektif bilinç ve anında iletişim imkanı sağlıyor olması da etkili olmuştur. Akıllı telefonlar üzerinden ileti, fotoğraf, video gibi öğelerin anında binlerce kişiyle paylaşılabiliyor olması, bu ağları kamuya açık alan haline getirmektedir. Bu da ileti ve fotoğraf paylaşan milyonlarca kişi demektir. Dolayısıyla bu, denetimi zor olan bir alan yaratmaktır. Denetimin zor olduğu bu alanda fotoğraf ve diğer paylaşımların binlerce kişinin elinden geçtiği varsayılırsa gerçek bir öğenin manipüle(yanıltmak) edilerek tekrar paylaşılarak propaganda malzemesi olarak kullanılmasının önüne geçilmenin de zorluğu anlaşılacaktır.

Fotoğraf bu yönüyle eğlendirmek, belgelendirmek, kanıt oluşturmak, propaganda yapmak gibi pek çok işlevde kullanılmıştır. Peter Turner, fotoğrafın tarihi kitabında şöyle demektedir; Fotoğrafın tarihi, gerçeğin ufak kopyalarının duyurulduğu yıl olan 1839'dan beridir, nerdeyse dünyanın tarihi ile eştir. Fotoğraf, dramların, krizlerin, savaşların devrim ve politik ayaklanmaların doğrudan temsilinin dışında, bir gözlemcisi olmuştur. Küçük bir araç olarak fotoğraf sanat, bilim, ticaret, felsefe ve teknolojinin kesişme noktasında yer alır(Turner, 1987, s.7). Fotoğrafın amacı, fotoğrafçının objektifini nereye çevirdiğine karar vermesinden itibaren başlar. Çekilen fotoğrafın nereden kırpılacağına, hangi yayın kuruluşunda yayınlanacağına ve fotoğrafın altına hangi başlığın yazılacağına karar vermek, tüm bunlar fotoğrafın kitle üzerinde bırakacağı etkiyi doğrudan etkileyen faktörlerdir. Fotoğrafın bu kadar farklı alanda, özellikle haber ve propaganda aracı olarak kullanılmasının nedeni şüphesiz ki dilinin evrensel oluşu ve sözlü - yazılı öğelere göre izleyeninde daha hızlı etki bırakıyor olmasıdır. Propaganda; başkalarını yazı, fotoğraf, film veya hitabet ile manipüle etme eylemidir. Sözlük anlamı, bir öğreti, düşünce veya inancı başkalarına tanıtmak, benimsetmek ve yaymak amacıyla söz, yazı vb. yollarla gerçekleştirilen çalışma,yaymacalardır (Tdk.gov.tr). Sontag'a göre; filmler ve televizyon programları duvarları ve ekranları aydınlatıp, onlara yansıyan ışıkları titreştirir ve sonra da kaybolup giderler; oysa, durağan fotoğraflarda rastlanılan görüntü kolayca biriktirilip saklanabilmektedir(Sontag, 2011, s.2). Bu da fotoğrafın diğer medya araçlarına göre kalıcılı̆̆ına işaret eder. Fotoğrafçılık doğrudan sonuca varmak açısından son derece uygundur. Kameranın önünde bir şey vardır; tek yapmanız gereken, onun fotoğrafını çekmektir(Freeman, 2012, s.9). Fotoğraf ayrıca etkisi uzun süreli olan bir araçtır. $\mathrm{Bu}$ da onu propaganda aracı olmasının bir başka sebebidir. Bu özellikleri fotoğrafı gündem oluşturmak için oldukça cazip bir öğe haline getirmektedir. "Fotoğraflar bize kanıt teşkil ederler. Hakkında bir şey işitip de şüpheyle karşılaştı̆̆ımız bir şey, onun fotoğrafı bize gösterildiğinde kanıtlanmış sayılır. Fotoğraf makinesinin faydalı olarak kullanıldığı alanlardan birisi, yaptığı kayıtla suçlayıcı bir nitelik taşımasıdır"'(Sontag, 2011, s.5). Fotoğraf gerçekleri yakalar, gerçeğe en yakın görüntüyü seyirciye sunar. Ancak deneyimlenen bir görüntünün üzerinden oynanmış olması gerçeği çarpıtabilmektedir. Bu şekilde farklı bir gerçeklik yaratılmış olur.

Manipülasyon ve propaganda birlikte düşünülmesi gereken kavramlardır. Birbirleirne hizmet ederek varlıklarını sürdürürler. Manipülasyon, fransızca kökenli bir kelime olup, bilgilerin seçilmesi, eklenmesi veya çıkarılması yoluyla elde edilen yeni görüntünün sunumu ile gerçekleşir. İletişim alanında sıkça karşılaşılan tanım, kitle iletişim araçlarının kitleleri tek yönlü haber 
Demirel, G. (2015). The power of the photograph in terms of manipulation and agenda setting. International Journal of Social Sciences and Education Research, 1 (2), 625-636.

akışıyla yanıltması ve hile yoluyla yönlendirmesiyle oluşturulmaktadır. Haber kaynağından gelen bilgi, üretiminden, tüketimine dek geçen süreçte yeniden kurgulanır ve izleyiciye farklı bağlamlarda sunulur(Frrat, 2008, s.22). Bu bağlamda manipülasyona en açık fotoğraflar haber fotoğraflarıdır. Haberin olmazsa olmazı 5N1K (Ne, Nerede, Ne zaman, Nasıl, Neden, Kim), kolayca değiştirilebilir kurallardır. Fotoğafta manipülasyon, görüntünün manipüle edilmesi, görüntünün kadrajlanarak manipüle edilmesi, görüntüye yazı eklenerek manipüle edilmesi, ve görüntünün kurgu yoluyla manipüle edilmesi şeklinde yapılabilmektedir. Manipülasyonun amacı bireysel olabileceği gibi kitlesel bir amaç da güdebilir.

Manipüle edilmiş fotoğraflarla yaratılan gerçekliklerle, toplumlar rahatlıkla manipüle edilebilmiş, ülkeler savaşa sokulmuş ya da savaşlara son verilebilmiştir. Bu da fotoğrafın ne denli güçlü bir propaganda aracı olduğunu tekrar kanıtlamaktadır. Fotoğraf makinasının pratikliği ve eylemlere doğrudan müdahalesi, makinenin çevrildiği yönü bazen önemsiz kılsa da, bazı konular göründüklerinin aksine, diğerlerin farklı olarak içlerinde daha derin anlamlar barındırıyor olabiliyor. Bir bütünden kesilmiş bir parça, ya da bir bütüne yönlendiren ufak bir parça. Fotoğrafçının gösterdiği konu katmanlardan oluşuyor, ve katman aşıldıkça daha büyük bir şeyi, bir fikri veya bir amacı barındırıyor olabilir. Manipüle edilen fotoğraf bir gerçeği saklıyor olabileceği gibi, bir yalanı da gösteriyor olabilir. Fotoğrafçının çektiği görüntü onun niyetinin göstergesidir ve fotoğrafın çekiminde ve çekim sonrası aşamalarında izlenecek tutumunu belirler. Yani göstermek istenen, fotoğrafçının konuyu ele alma biçimini belirler (Freeman, 2012, s.10).

Bugünün dijital teknolojisi, fotoğraf düzenleme işlemlerinin eski tip karanlık odalardan çıkıp, bilgisayar ve telefon uygulamalarıyla yapılmasına ve fotoğrafa uygulanacak görsel manipülasyon yönteminin çeşitlenmesine, pratikleşmesine imkan sağlamıştır. Dijital manipülasyon bir el sanatıdır; kısmen bilim, kısmen de sanatçılıktır. En basit hilelere hakim olmak ve programın temin edebileceği verilerin zenginliğini anlamak çok önemlidir(George, 2014, s.210). Yapılan fotoğraf manipülasyonları fotoğrafçının kadrajını ayarlarken uyguladığının yanında ideolojik amaçlar için editörlerin ve dijital manipülasyon konusunda uzman olan kişilerin müdahalesiyle de oluşturulmaktadır. "Gerek propaganda eylemini biçimlendirmesi açısından, gerekse propaganda yapan öznenin zihinsel süreçlerine olan etkisi bakımından ideoloji, propagandayla birlikte ele alınması gereken temel bir kavramdır"(Firat, 2008, s.2).

Yapılan manipülasyonların büyük bir çoğunluğunun amacı kitleler üzerinde uyguladıkları propagandalarına destek sağlamak ve böylece taraftar toplamaktır. Fotoğraflanan bir görüntü gerçeğin birebir yansıtıcı olmasa da, gerçeğin birer temsillerini oluşturmaktadırlar. Daha önceden zemini oluşturulan kurmaca gerçekliğin içindeki bireyler sağlayıcıdan gelen iletilere karşı sorgu aşamasında değillerdir. Dolayısıyla inandırıldıkları davalarına kendilerini daha da inandırıp bağlayacak öğelerin gerçekliğini sorgulamadan bağlanmaları da bu yüzdendir. "Bir görüntünün fotoğraf makinesiyle kayda geçirilmesinin başka bir özelliği, onun doğrulayıcı, haklı çıkarıcı işlevidir. Bir fotoğraf verili bir olayın gerçekleşmiş olduğunun su götürmez kanıtıdır. Çekilmiş olan resmin çarpıtılmış olması mümkündür, her zaman için, o fotoğraftakine benzer bir şeyin mevcut olduğuna ya da olmadığına dair bir kanıya kapılmamızı sağladığı da açıktır”(Sontag, 2011, s.5). Fotoğraf, görsel öğe olduğundan dolayı inandırıcılığı daha yüksek bir propaganda aracıdır. Fotoğraf -doğru ya da değil- kanıt niteliğindedir, üretilmesi kolaydır, kısmen ucuzdur, biriktirilmesi, saklanması ve korunması oldukça kolaydır. Fotoğrafın ilk yıllarında güzel anların kayıtlanıp saklanması amacıyla kullanılmış olması bu pratikliğinden kaynaklanmaktaydı. Ancak; zamanla fotoğraf olayların aktarımında toplumları etkilemek, gündem oluşturarak kamuoyu oluşturmak 
Demirel, G. (2015). Fotoğrafın manipülasyon ve gündem saptama gücü. International Journal of Social Sciences and Education Research, 1 (2), 625-636.

amacıyla kullanılmaya başlanmıştır. Toplumun olaylar hakkında bilgi kaynağı olan yazılı basında da fotoğrafların haberin yanında kullanılması, haberlerin inandırıcıllı̆ını arttırarak, basına olan güveni arttırmıştır.

Manipülasyon ve propaganda denince akla gelen ilk insanlardan olan Hitler; Kavgam kitabında, kitleleri sadece hitap ve emirlerle yönlendiremeyeceğinin farkında olduğundan dolayı propagandaya bu kadar önem verdiğinden bahseder. Propagandanın önemimin fakrında olan diğer pek çok devlet adamı, ülke, kurum ve kuruluşlar, manipülasyonu hala etkin bir şekilde kullanmaktadırlar. Fotoğrafik manipülasyon ve propagandanın, özellikle de teknolojinin bu denli geliştiği, dünyanın dijitalleşerek uzak mesafelerin ortadan kalktığı, sanal bir dünya ve dilin oluşmuş olması ve ne önemlisi de manipülasyon ve propagandanın teknoloji ile çok daha kolay yapılabiliyor olması onu bugünün yaşanan toplumsal olaylarının da vazgeçilmez bir öğesi haline getirmiştir. Bu sınırsız ve hızlı paylaşım alanında sosyal medyanın da çok büyük etkiye sahip olduğunu belirtmekte fayda var.

Aşağıda manipüle edilmiş eski ve güncel haber fotoğraflarının açıklaması yer almaktadır.

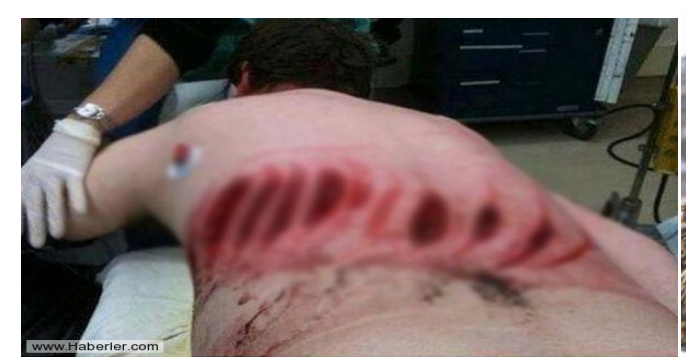

Fotoğraf 1

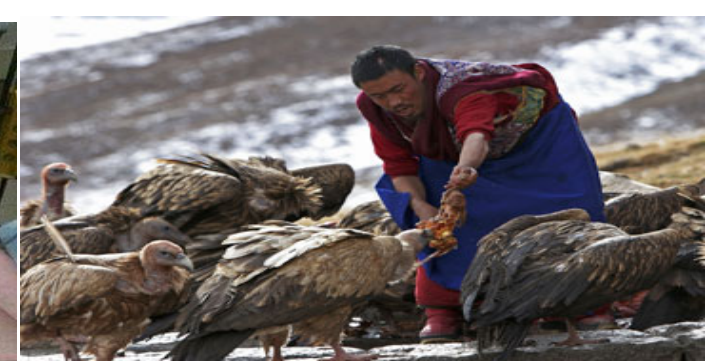

Fotoğraf 2 (Temsili)

Fotoğraf 1'de yer alan genç, taksim gezi olaylarında ne çok paylaşılan fotoğraflar arasında yer almaktaydı, polisin göstericilere orantısız güç kullanımının ispatı olarak sosyal medyada paylaş1lan ve büyük bir kitle tarafından tepkiyle karşılana bu fotoğraf yurtdışından bir bot kazasından alınmış bir fotoğraftı. Fotoğrafın belirli kısımlarının kırpılmasından dolayı, ilk başta kimlik ve mekan tespiti yapmak olanaksızdı. Gerçek sonradan başka sosyal medya kullanıcılarının fotoğrafın orijinalini bulup paylaşmasıyla ortaya çıktı (http://www.forum renkli.com).

Fotoğraf 2'de bir adam elinde insan eti ile akbabaları beslemektedir. Bu ve buna benzer hatta çok daha korkunç ceset fotoğrafları ilk önce Sosyal medya da daha sonra da yazılı ve görsel basında, Çin hükümetinin Doğu Türkistan halkına yaptığı zulmün, işkencenin kanıtı olarak belirtildi. Bu fotoğrafların haber sitelerinden ve sosyal medyada yer alması Türkiye de büyük bir kamuoyu oluşturdu. Bunun sonucunda da bir çok il ve ilçede protestolar, yağmalar, darplar başladı, öyle ki Çin hükümeti Türkiye'yi Ziyaret edecek vatandaşlarına uyarıda bulundu. Ancak medyada dolaşan haberler eski olmakla birlikte paylaşılan parçalanmış ceset fotoğraflar Tibet keşişlerinin inanışları gereği ölen keşişlerini defnetme yöntemleriydi. 'Sky Burial'(gök defin) olarak adlandırdıkları bu yöntemle bedenlerini parçaladıkları cesetlerin akbaba ve diğer canlılar tarafından yenmesini sağlayarak, başka bir canlıda tekrar hayat bulacaklarına inanır. Bu ayinden alınan görüntülerin kırpılarak, altına yazılar yazılarak manipüle edilmesi ve Doğu Türkistan propagandasının sosyal medyada yapılması günlerce devam etmiştir (https://en.wiki-pedia.org/wiki/Sky_burial). 
Demirel, G. (2015). The power of the photograph in terms of manipulation and agenda setting. International Journal of Social Sciences and Education Research, 1 (2), 625-636.

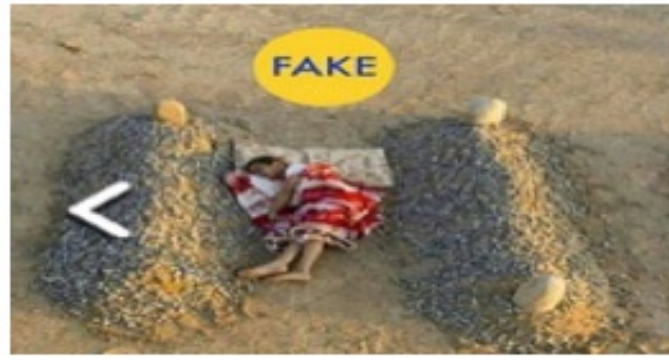

Fotoğraf 3

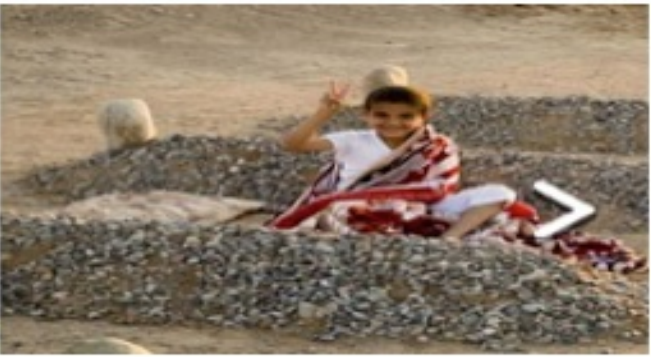

Fotoğraf 4

Fotoğraf 3'te iki mezar arasında uyuyan bir çocuk görüntüsü vardır. Sosyal medyada günlerce dolaşan bu fotoğraf, çeşitli haber sitelerinde Suriye savaşı ile ilişkilendirilerek propaganda yapıldı. Fotoğraf Suudi fotoğrafçı Abdulaziz Uteybi'ye ait. Fotoğrafta görülen çocuk da fotoğrafçının kendi yeğeni. Gördüğü 3 toprak yükseltiye mezar süsü vererek yeğenini ortaya koyarak battaniyesine sarılmış masum bir çocuk fotoğrafı elde ediyor. Fotoğrafın gerçek hali de 4. Fotoğraftır, görüldüğü üzere gayet sevinçli ve dram yaşamayan bir çocuktur. Bu fotoğrafı paylaşmasıyla farklı kişilerin de eline geçiyor ve sonuç kırpılarak manipüle edilen ve propaganda malzemesi yapılan bir fotoğraf (http://www.usasabah.com).

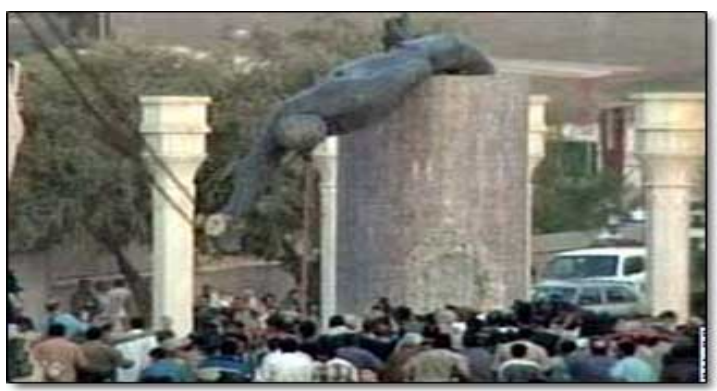

Fotoğraf 5

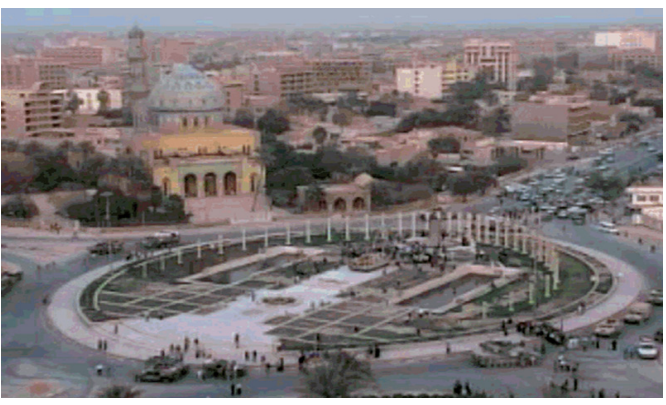

Fotoğraf 6

Firdevsi meydanı olayı olarak geçen bu fotoğrafta Amerikan'ın Irak işgali sırasında Saddam heykelinin devrilmesinin görüntüsü verilmektedir. 5. Fotoğrafta toplanan çok fazla halk görüntüsü verilirken, 6. Fotoğrafta aynı gün meydandan çekilen bir fotoğraf gözükmektedir. Üstten çekilen fotoğrafta kalabalığın çok az olduğu meydanın boş olduğu görünür. Bu paylaşılan fotoğraf Amerikan propagandasının bir ürünüdür ve Irak halkının da desteğini aldıklarını kamuoyuna bu şekilde göstermeye çalışmışlardır.
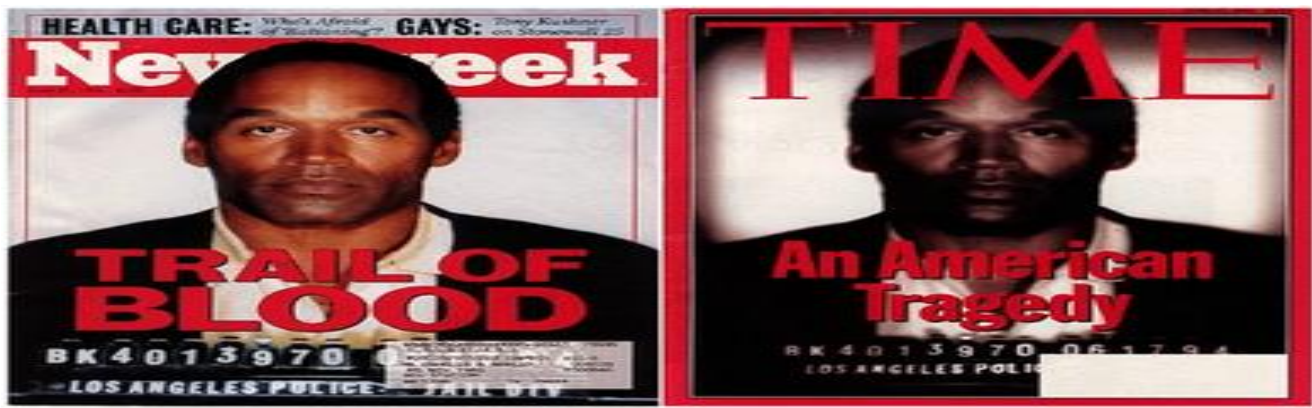

Fotoğraf 7

Amerikalı sporcu O.J. Simpson'un eşini öldürme şüphesiyle gözaltına alındığının gösterildiği iki ayrı derginin kapakları gösterilmektedir. Fotoğrafın ışı̆̆ıyla oynanarak fotoğraf manipüle edil- 
Demirel, G. (2015). Fotoğrafın manipülasyon ve gündem saptama gücü. International Journal of Social Sciences and Education Research, 1 (2), 625-636.

miş ve zanlı kamuoyuna korkunç gösterilerek onun hakkında olumsuz kanının oluşması sağlanmıştır. Renk üzerinde yapılan ve sonuçta etik tartışmalara yol açan müdahale, Time dergisinin 1994 yılındaki kapağında kullanılmıştır(Korkmaz, 2014, s.47). Bu şekilde müdahale edilmiş fotoğrafın yayınlanmasına izin veren editör ırkçılıkla suçlanmıştır. Dergi ırkçılıkla suçlanınca editör, fotoğrafın sertliğini, amansız parlak ışığın, Simson'un yüzündeki birkaç günlük sakalın düzeltildiğini ve böylece Simpson'u trajik bir ikon haline getirdiklerini savunmasında bulunur. Bir başka ifade ile onu olmasını istedikleri şekle dönüştürmüşlerdir (Soygüder, 2013, s.661).

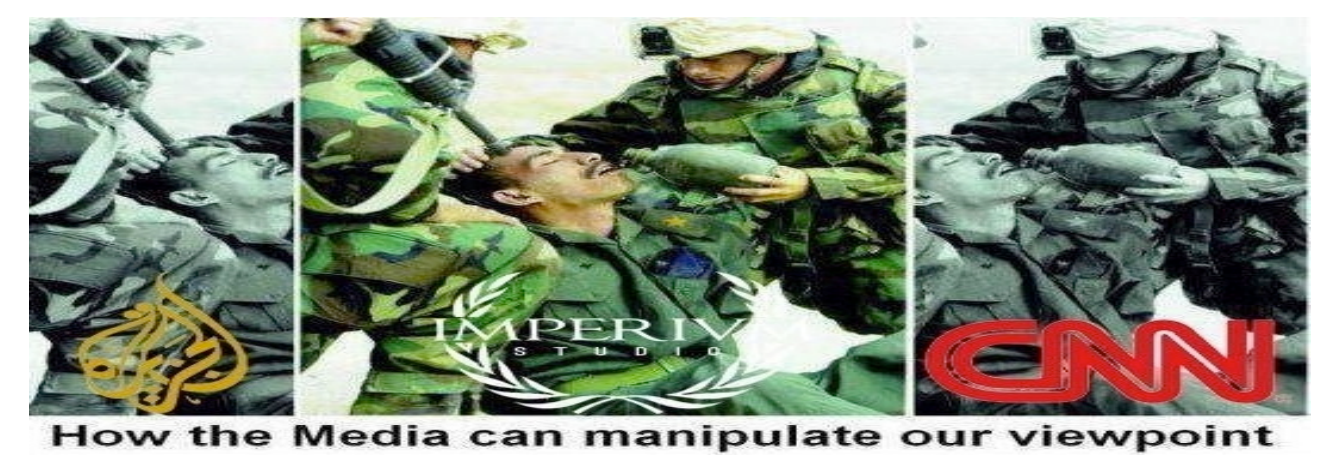

\section{Fotoğraf 8}

Bir görüntünün üç farklı haber ajansının AL JAZEERA, IMPERIV ve CNN açılarından nasıl gözüktüğünün fotoğrafı. Manipülasyonun özeti. Bu ajanslarının farklı yerlerden kırpılmış fotoğrafı bültenlerine taşıdığı düşünüldüğünde bir fotoğrafin ufak bir kırpma hareketiyle anlamını ne kadar değiştiği de anlaşılmış olacaktır.

Fotoğrafın sadece manipüle etme gücünün olmadığı aynı zamanda gündemde olmayan konulara ya da gündemde olması gereken konulara da değinerek kamuoyu oluşturduğu da açıktır. Aşağıda bir eski bir de güncel olmak üzere fotoğrafın faydasının gösterildiği iki fotoğraf ve gündem oluşturma örneği yer almaktadır.

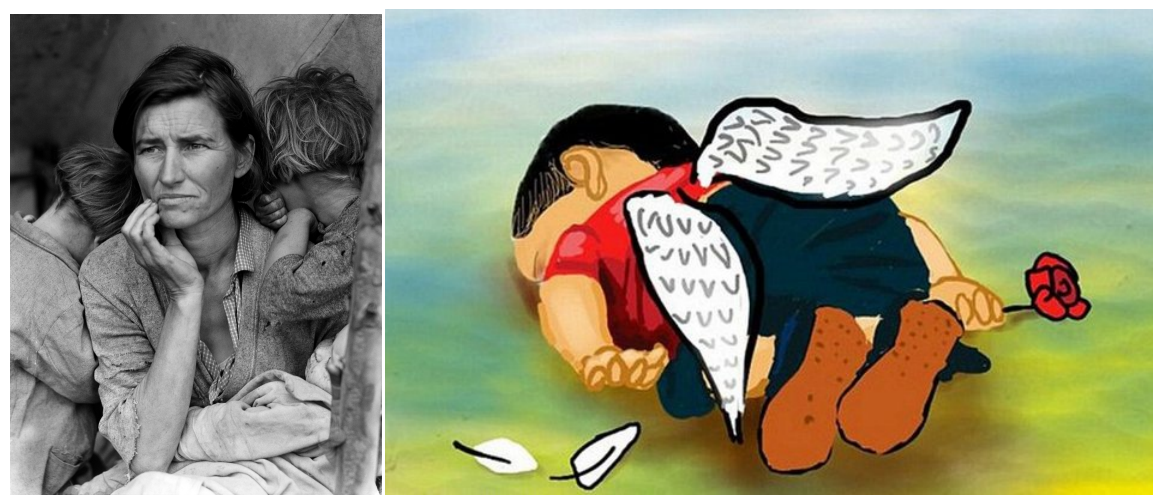

Fotoğraf 9

Fotoğraf 10 (Temsili)

Kendisine sarılmış iki çocuğuyla oldukça düşünceli duran bir kadının fotoğrafı olan 9. fotoğraf, Ünlü fotoğraf sanatçısı Dorothea Lange'nin 'göçmen anne' adlı fotoğraftır. Sanatçı '1929 Büyük Bunalım' yıllarını, insanların dramlarını, açlığı fotoğraflamak için çalışmalar başlatmıştır. Yoksul insanları fotoğrafladığı bu çalışmalarından biri olan 'Göçmen Anne' fotoğrafi ve bunun gibi fotoğrafları kamuoyunda büyük yankı uyandırmış ve devletin bundan sonra göçmenler için kamp kurmasına vesile olmuştur. Bu fotoğraf sayesinden yoksul insanların dramı gündeme getirilerek onlar yararına bir adım atılması sağlanmıştır (https://tr.wikipedia.org/wiki/Dorothea_Lange). 
Demirel, G. (2015). The power of the photograph in terms of manipulation and agenda setting. International Journal of Social Sciences and Education Research, 1 (2), 625-636.

10. Fotoğraf ise oldukça güncel bir olaya ait bir fotoğraf. Suriye iç savaşından kaçan göçmenlerin deniz yoluyla Avrupa'ya geçmek isterken bindikleri botun batması soncu 3 yaşındaki Aylan Kurdi isimli çocuğun cansız bedeni kıyıya vurur, bu fotoğraf hem yazılı, hem görsel hem de sosyal medyada günlerce gündemde kalarak dünya genelinde mülteci krizi ile ilgili büyük bir kamuoyu oluşmasının önünü açtı. Kapılarını mültecilere açmayan Avrupa ülkelerine bu fotoğraftan sonra büyük bir tepki gelince, Avrupa ülkeleri sınırlı da olsa kapılarını Suriyeli göçmenlere açmış oldu. Küçük bir çocuğun cansız bedeninin denize vurulması, şüphesiz dramatik bir olaydır ve propaganda yapılmamalıdır ancak, fotoğrafın mültecileri gündeme taşıyı kamuoyu oluşturması ile bu küçük beden sayesinden binlerce insanın da hayat kurtulmuş oldu.

\section{Sonuç}

Fotoğrafın, özellikle de basında kullanılan fotoğrafların geniş kitleler tarafından anlaşılabilirliği ve toplumsal boyutta kullanılabilen bir kitle iletişim aracı olma özelliği, onun her geçen gün daha da etkili ve fazla bir biçimde medyada yer almasına neden olmuştur. Bu özelliğiyle fotoğraf dünyada çeşitli dönemlerde kullanılmış ve kullanılmaya da devam edecektir. Bireysel kullanıcılar olarak insanlar, gelen bir iletiye güvenilir kaynaklar süzgecinde geçirdikten sonra, inanmayı ya da inanmamayı seçmelidir. Kısaca kitlesel hareketlerin çok kolay manipüle edilebildiği bu elektronik çağda otokontrolün önemi çok daha elzem hale gelmiştir.

\section{Kaynakça}

Czaja, P. C. (1973). Writing With Light, a Simple Workshop in Basic Photograhy, The Chatham Press, Inc. Connecticut,

Çizgen, G. (1992). Fotoğrafin Yapısı ve Kimliği Üzerine Denemeler, İstanbul: Ataol Yayınc1lı.

Firat, N.S. (2008). Savaş Fotoğraflarının kullanımı Bağlamında Propaganda ve Manipülasyon, Yüksek Lisans Tezi, Marmara Üniversitesi, İstanbul,

Freeman, M. (2012). Fotoğrafçııın Zihni, Daha Başarılı dijital Fotoğraflar için Yaratıcı Düşünme, Çev. Seda Çıngay, İstanbul: Remzi Kitapevi.

George, C. (2014). A'dan Z'ye Dijital Fotoğrafçıllk, Çev. Bala Toprak, İstanbul: İnkılap Kitapevi.

Kirkman, D.M. (1983). How to Use \& Display Your Pictures, HPBooks,USA,

Korkmaz, A. (2014). Etik Bağlamda Haber Fotoğrafçılığının Manipülasyon ve Propaganda Aracı Olarak Kullanılmasının Değerlendirilmesi, Gümüşhane Üni. İletişim Fak. Elektronik Dergisi, Cilt:2, Sayı:4, Gümüşhane,

Smith, B. (2001). Designing a Photograph, Visual Techniques For Making Your Photographs Work, New York: Watson- guptill Publication.

Sontag, S. (2011). Fotoğraf Üzerine, Çev, Osman Akınhay, İstanbul: Agora Kitaplığı.

Soygüder, Ş. (2013). Fotoğraf Editörlüğü Kurumu ve Gazeteler için Önemi”, International Journal of Social Science, Cilt: 6 Say1: 2,

Turner, P. (1987). History of Photography, England: Hamlyn Publishing.

http://www.tdk.gov.tr/index.php?option=com bts\&arama=kelime\&guid=TDK.GTS.56255ca1852ca8.85372828,E.T: 20.10 .2015

http://www.ushmm.org/wlc/tr/article.php?ModuleId=10005202, E.T: 20.10 .2015 
Demirel, G. (2015). Fotoğrafın manipülasyon ve gündem saptama gücü. International Journal of Social Sciences and Education Research, 1 (2), 625-636.

http://www.arsivfotoritim.com/yazi/ali-ihsan-okten-bir-siyasal-propaganda-araci-olarak-fotograf/,

20.10 .2015

http://www.usasabah.com/Yazarlar/taha kilinc/2014/01/20/kalpler-hizla-olurken, E.T: 20.10.2015

https://en.wikipedia.org/wiki/Sky_burial, E.T: 20.10.2015

https://tr.wikipedia.org/wiki/Dorothea Lange, E.T: 20.10.2015

http://www.forumrenkli.com/turkiyeden-haberler/94866-twitter-da-inanilmaz-gezi-parki-iftirasi.html,

$$
\text { E.T: } 20.10 .2015
$$

Fotoğrafl:http://www.hastane.com.tr/taksim-olaylarinda-sosyal-medya-yalanlari-galerisi-sayfa-2.html, E.T: 20.10 .2015

Fotoğraf2:http://people.howstuffworks.com/culture-traditions/cultural-traditions/sky-burial2.htm,

E.T: 20.10 .2015

Fotoğraf 3: http://www.mavikocaeli.com.tr/images/99999999.jpg, E.T: 20.10.2015

Fotoğraf 4: http://www.mavikocaeli.com.tr/images/99999999.jpg,E.T: 20.10.2015

Fotoğraf 5: http://arsiv.ntv.com.tr/news/209701.asp, E.T: 20.10.2015

Fotoğraf6:http://gawker.com/should-the-ap-really-have-fired-this-pulitzer-prize-war-1507309131,

E.T: 20.10.2015

Fotoğraf7:http://tvxs.gr/news/blogarontas/diki-o-j-simpson-mia-ypothesi-poy-allakse-dikonomiko-systima-ton-ipa, E.T: 20.10.2015

Fotoğraf8:http://regionalpost.com/how-the-media-can-manipulate-our-viewpoint/,E.T: 20.10.2015

Fotoğraf9:https://tr.wikipedia.org/wiki/Dorothea_Lange\#/media/File:Lange-MigrantMother02.jpg, E.T: 20.10 .2015

Fotoğraf10:https://tr.instela.com/kiyiya-vuran-insanlik--10441861,E.T: 20.10.2015 
Demirel, G. (2015). The power of the photograph in terms of manipulation and agenda setting. International

Journal of Social Sciences and Education Research, 1 (2), 625-636.

\section{Extended abstract in English}

The adventure of the photograph has a long story. The invention of photograph and its improvement in time witness history at the same time. Photograph has brought many debates, such as whether or not photography is an art, the relationship between photograph and photographer, the relationship between photographer and his/her subject matter, if the photograph is genuine or is it all a fiction, the relationship between photograph and the other science and art fields within developmental stages. Despite of all discussions and speculations, the immediate impact and permanence of photograph is indisputably clear.

The acceleration of photography is highly impressive and scientifically evident. DSRL machines, Photoshop, smart phones and its photograph apps such as Instagram are very effective on photograph's improvement and popularity. Since it is cheap and practical, reaching photography equipment has become easier than ever and results in a growing number of population interested in photography. Social media tools which are the fashion of recent years let people share the photographs taken with other people. It is clear that these speedy developments have contributed a lot to photograph art, but there stands the other side of the medallion. Photograph art needs only seeing to understand because it immediately affects the visual memory and it has a universal language. For that reason, it is used commonly by individuals and corporations. One of the usages of photograph is to impress public opinion in the periods when social sensitivity is intensive, to trail masses just like the periods of war, natural disasters, or mass actions. Such kind of use may be defined as propaganda. Propaganda is the action of manipulating the others by writings, photographs, films or declamation. The lexical meaning of propaganda is the studies realized by statements, writings, etc. to represent, adopt and spread a doctrine, an idea or a belief. Films and TV programs enlighten walls and screens, vibrate the lights reflecting and they disappear. However, the view met on stable photographs can be easily collected and kept. This indicates the permanence of photograph rather than the other media tools. Photography is profoundly available for coming to a conclusion. There is only one thing in front of the camera; the only thing to do is to take its photo. When it comes to propaganda, manipulation should be evaluated with it because propaganda and manipulation work together and create an effect on masses. Manipulation is a French-rooted word and it realizes with the representation of the new view by selecting, adding or reducing the information. The definition encountered mostly in communication field is formed by misleading of mass communication by one-way news feed and their tricky direction. The information coming from news source is re-fictionalized in the process from production to consumption and it is represented to the audience in different concepts. Propaganda or manipulation starts from the person who uses the device just like it occurs for the other media tools. The aim of the photograph starts from the moment where photographer decides to turn his/her objective. To adjust the frame of the photograph, the point where the photograph is cropped, where it is going to be published and decide on the text to be written under it is to make photographer is the one who makes propaganda first. All of them are the factors directly affect the impress of the photograph on mass.

If we are to affect the crowds and to take on board newsworthiness, 'news photos' must be especially mentioned because news photos are the most vulnerable ones to manipulation.

The indispensable $5 \mathrm{ws}$ and $1 \mathrm{~h}$ (What, where, when, why, which, who, how) are easily changed rules. Manipulation in photos can be done by manipulating images, manipulating image via viewfinder, adding some texts and editing by fiction. The aim of manipulation can be individual and 
Demirel, G. (2015). Fotoğrafın manipülasyon ve gündem saptama gücü. International Journal of Social Sciences and Education Research, 1 (2), 625-636.

also massive. The photo shots taken by the news agency in accordance with their ideology and the photographer's decision on the crowds about what they may see or may not are very easy. That's why we get 3 different deductions from the same news from 3 different angles. Ideological point of view is a basic concept which is to be handled with propaganda in terms of both forming propaganda and the effect of the subject making propaganda on mental processes. In other words, it is impossible to think propaganda totally apart from ideology. The reason for the news agencies' putting photos on their news text is a strategy applied in accordance with this ideology. Plausibility increases with the photos put into the news text.

Photograph is an eye-pleasing art as well as universal. Apart from stopping the time, it is easier to store, protect and archive the data via photographs compared to other fields of art. Another reason why photographs are so popular is its advantage. These archiving and protecting qualities get much easier with the invention of digital cameras and digital data storage devices. Printed photo albums are now conveniently transferred into digital media. All the improvements about photographs contain both aesthetic and ideological factors in themselves. Using photos in various fields, and its practicability and lucidity makes it popular. Photos have more permanent effect in comparison with written or oral items, which makes it more attractive to become a current issue.

Propaganda with photographs used by political powers nearly in all periods in the past are going to be used in the future because it is possible to mold public opinion, start or and wars via some manipulated photos which have powerful effect on masses. All these reveal how powerful photograph is and why it is used as a propaganda tool is. 